\title{
Fabricando el Sur. Colectivos ciudadanos se unen para la defensa del patrimonio industrial andaluz
}

Ante la gravísima situación por la que atraviesa el patrimonio industrial andaluz, el pasado 9 de marzo de 2013, se constituyó en Sevilla la Coordinadora Andaluza de Patrimonio Industrial Fabricando el Sur (fabricandoelsur.wordpress.com/). Las conclusiones del encuentro consistieron en la identificación de los factores que están en la base de la problemática actual que afecta a estos bienes. Todo ello en un escenario marcado por la ausencia de una planificación integral de los recursos patrimoniales generados por la industrialización andaluza.

Coordinadora Andaluza de Colectivos en Defensa del Patrimonio Industrial Fabricando el Sur

URL de la contribución <www.iaph.es/revistaph/index.php/revistaph/article/view/3389>

El día 9 de marzo de 2013 quedó constituida, en la sede de la cooperativa Tramallol (Sevilla), tras ser convocados por la plataforma ciudadana Salvemos la Fábrica de Vidrio la Trinidad, la Coordinadora Andaluza de Colectivos en Defensa del Patrimonio Industrial, denominada Fabricando el Sur.

La citada coordinadora ha surgido como una iniciativa ciudadana que pretende generar una respuesta común ante la gravísima situación por la que atraviesa el patrimonio industrial andaluz. Está formada por 21 asociaciones que tienen entre sus objetivos la defensa de los bienes del patrimonio industrial. Durante la sesión constituyente se expusieron los casos específicos y las reivindicaciones de cada una de las asociaciones asistentes. Una primera puesta en común que sirvió para detectar los principales factores que afectan y ponen en peligro estos bienes: los impactos especulativos de las transformaciones urbanas y territoriales, el expolio de importantes testimonios patrimoniales, la realización de proyectos de intervención sobre zonas patrimoniales industriales carentes de rigor científico, la desaparición física de las personas que protagonizaron los hechos industriales, la destrucción física de importantes archivos y la inexistencia de una estructura museográfica andaluza de este sector.

Los colectivos integrantes de Fabricando el Sur expusieron su intención de contribuir con la experiencia acumulada en estos años a resolver esta delicada situa- ción, ya que, en estos momentos de crisis, son necesarias propuestas viables para la protección y activación del patrimonio industrial que contemplen la renovación metodológica en su análisis y la eficiencia en la gestión de tan importantes recursos.

Para ello la coordinadora reclama que la Junta de Andalucía, desde la Consejería de Educación, Cultura y Deporte, diseñe, mediante un modelo participativo, una estrategia planificada que aborde, desde ahora hasta un medio plazo, cifrado en diez años, las siguientes medidas:

- la creación de una comisión andaluza de patrimonio industrial, que es un tema pendiente, al existir el resto de comisiones de patrimonio (etnográfico, mueble, museos, archivos, arqueológico e inmueble); este órgano, además de asesorar e informar sobre asuntos específicos, tendría por misión principal la elaboración de un plan estratégico del patrimonio industrial de Andalucía (objetivos, metodología, equipos, plazos y financiación);

- atender los casos más urgentes de catalogación, protección o intervención sobre bienes industriales en peligro como son: la fábrica de vidrio de la Trinidad, el cerco industrial de Peñarroya-Pueblonuevo, el silo de mineral popularmente conocido como Toblerone de Almería, la fábrica de azúcar San Isidro de Granada, la fábrica del Tarajal de Málaga, la fábrica de San Joaquín de Nerja, el patrimonio ferroviario de Tharsis y el patrimonio científico de los institutos históricos andaluces. 


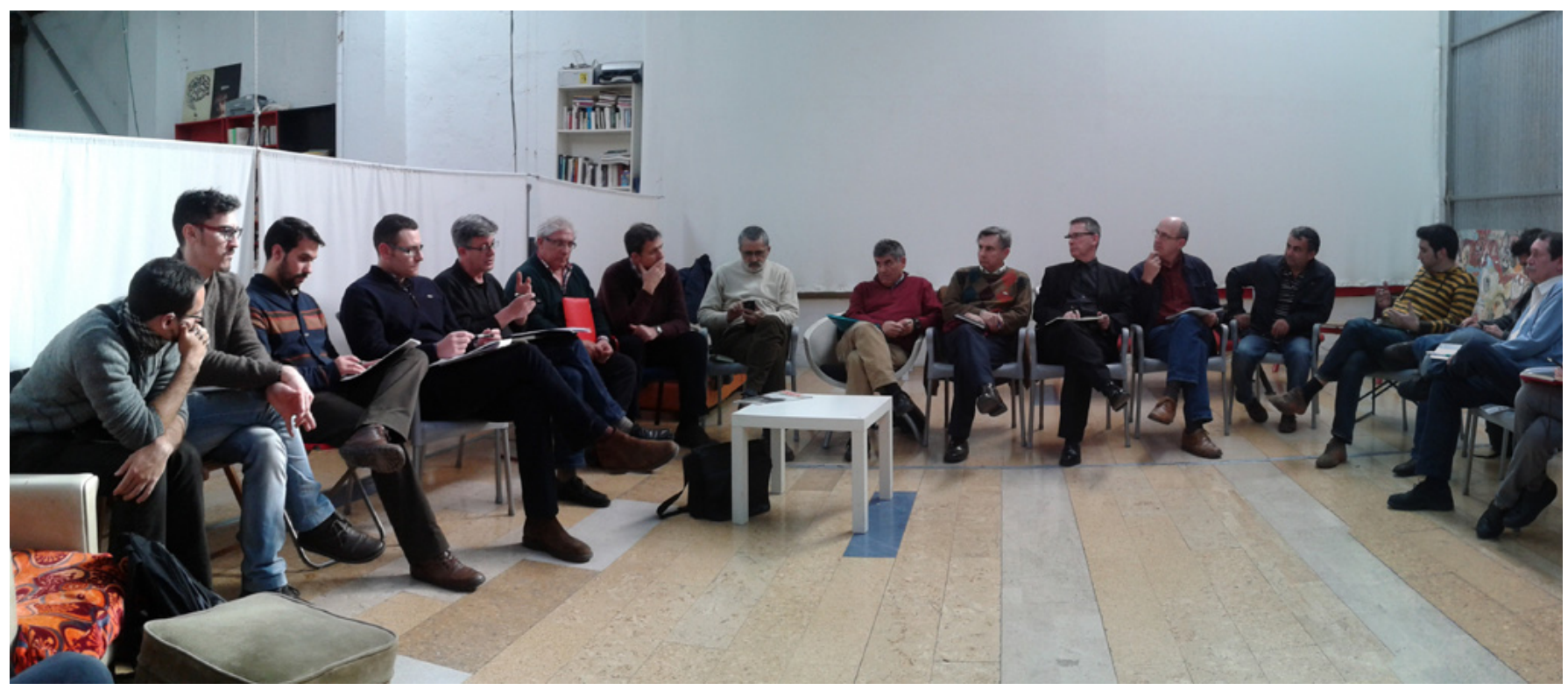

Miembros de la Coordinadora en el acto de fundación el 9 de marzo de 2013 | foto Coordinadora Fabricando el Sur

Esta reflexión, que debe trasladarse a la sociedad andaluza, verdadera destinataria de estas demandas, y que debe vehicular la administración pública, parte de un análisis del contexto cultural en el que se forjaron los hitos históricos de la industrialización andaluza, que hoy es mejor conocida gracias a la labor desarrollada por las universidades, grupos de investigación y colectivos de defensa del patrimonio industrial. Procesos de un extraordinario valor histórico, y por tanto patrimonial, que han legado un amplio sistema de bienes culturales como son:

- las arquitecturas industriales, de amplia implantación en Andalucía, los edificios, como contenedores en los que destacan su tipología, estructura, construcción, programa y estilos, en relación tanto con códigos, sistemas y proyectos externos, como a aquellos otros desarrollados desde Andalucía;

- las maquinarias y herramientas industriales, tales como las productoras de energía, de movilidad o de transformación, así como las herramientas y las infraestructuras necesarias para la producción, almacenaje o distribución (entendidos estos objetos tecnológicos desde las innovaciones externas y las producidas en la misma Andalucía);
- Ios archivos del trabajo, compuestos por documentos empresariales como son los manuales de instrucción, los planos de arquitectura, máquinas o instalaciones o los registros administrativos de carácter legal, social o económico;

- todo ello en un contexto global, que denominamos cultura industrial, compuesta por los conocimientos técnicos, los procedimientos, la evolución de las condiciones de trabajo, el movimiento sindical o las manifestaciones simbólicas tales como festividades, conmemoraciones, así como cualesquiera otras manifestaciones en las que las ideas están mediatizadas por la cultura del trabajo, y que conforman testimonios de la vida de los trabajadores, empresarios o técnicos, como fueron los de la organización laboral, la estructura de los oficios, los conocimientos técnicos, los modelos de organización empresarial, las luchas sindicales, las tipologías residenciales y los equipamientos relacionados con las actividades productivas;

- sin olvidar la dimensión territorial que se expresa en los actuales paisajes industriales.

La coordinadora considera que la resolución de estos problemas es viable, siempre que se aborde de una forma 
integral, coordinada, rigurosa y participativa, generando una nueva dinámica de trabajo entre las administraciones públicas y las entidades ciudadanas. Para la coordinadora, es el momento adecuado y necesario para iniciar en Andalucía un proceso de protección y activación del patrimonio industrial que nos aproxime a los logros que estas políticas transversales están adquiriendo en el contexto internacional, máxime cuando el año de 2015 ha sido declarado por el Consejo de Europa como Año Europeo del Patrimonio Industrial. Cita a la que nuestra comunidad autónoma debe llegar en las mejores condiciones para ofrecer una situación de normalidad en todo lo que afecta a la gestión de estos bienes culturales.

Fabricando el Sur pretende fortalecer las relaciones y los vínculos establecidos entre la población y el territorio, entre la memoria y la contemporaneidad, entre el espacio y la tecnología, a través de un enfoque socialmente comprometido y experimental; con la intención de desarrollar un nuevo contexto contemporáneo, un espacio simbiótico y de transición sobre las estructuras industriales abandonadas, el territorio, la creación contemporánea y las nuevas formas de producción de nuestro tiempo; ensayando un modelo que sea capaz de integrar armónicamente, desde objetivos sociales, el sector público y el privado, conectando el espacio urbano con el rural y el natural; para ofrecer nuevas formas de habitar, de trabajar, de investigar, de comunicar, de socializar y de producir, que colonicen críticamente y se insertan respetuosamente, en los viejos contenedores e infraestructuras fabriles.

\section{Entidades que conforman la Coordinadora Andaluza de Colectivos en Defensa del Patrimonio Industrial Fabricando el Sur}

> Asociación de Amigos del Ferrocarril de Almería

> Asociación de Amigos del Molino de Gines (Sevilla)

$>$ Asociación para la Conservación y Difusión del Patrimonio Histórico "La Volaera" de Nerja (Málaga)

$>$ Asociación Cultural Cordobesa de Amigos del Ferrocarril

$>$ Asociación Cultural Lieva de la Sierra de Aracena (Huelva)

$>$ Asociación en Defensa de las Chimeneas y del Patrimonio Industrial (Málaga)

> Asociación Granadina de Amigos del Ferrocarril y del Tranvía (Granada)

> Asociación Planuente Puente Metálico Alfonso XIII (Sevilla)

> Asociación Histórica Retiro Obrero (Sevilla)

> Asociación La Maquinilla de Peñarroya-Pueblonuevo (Córdoba)

$>$ Asociación Sevillana de Amigos del Ferrocarril (Sevilla)

$>$ Asociación Salvemos el Toblerone (Almería)

$>$ Cooperativa Tramallol (Sevilla)

$>$ Colectivo Proyecto Arrayanes de Linares (Jaén)

$>$ Fundación Riotinto (Huelva)

$>$ Plataforma Ciudadana Salvemos la Fábrica de Vidrio la Trinidad (Sevilla)

> Plataforma en Defensa del Museo del Azúcar de Torre del Mar (Málaga)

> Grupo de Estudios Silos y Graneros

$>$ Sección española del International Committee for the Conservation of the Industrial Heritage (TICCIH-España) 